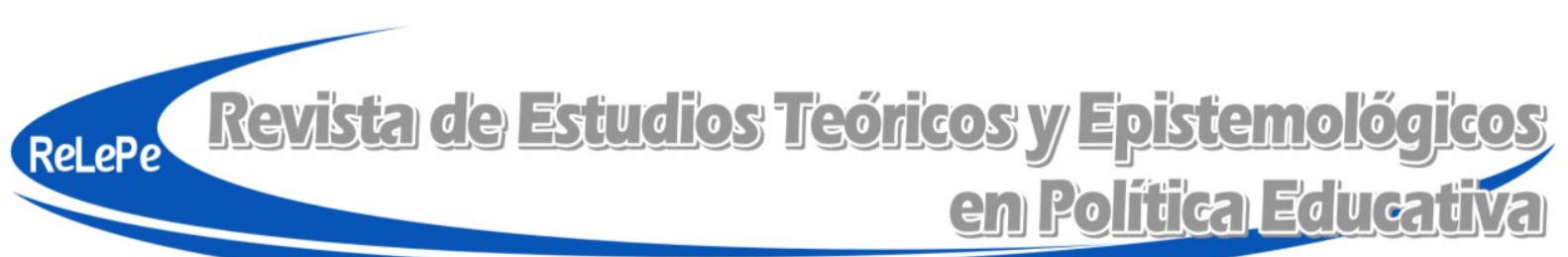

ISSN 2409-3696

DOI: $10.5212 /$ retepe.v.4.002

\title{
Pesquisa em Políticas Educacionais: escolhas temáticas e fontes em debate $(2000-2010)^{*}$
}

\author{
Antonia Almeida Silva \\ Universidade Estadual de Feira de Santana (UEFS) \\ antoniasilv@gmail.com \\ Márcia Aparecida Jacomini \\ Universidade Federal de São Paulo (Unifesp) \\ jacominimarcia@gmail.com
}

\begin{abstract}
Resumo: O estudo problematiza as características das pesquisas de mestrado e doutorado e seus delineamentos quanto às escolhas temáticas e às fontes de pesquisa no campo das políticas educacionais. Para isso, valemo-nos de um banco de teses e dissertações defendidas no período de 2000 a 2010 em programas de pós-graduação em educação no Brasil, organizado por duas pesquisas desenvolvidas entre 2012 e 2017, o que permite o debate entre achados empíricos e análises de autores influentes na área, identificados como aqueles mais referidos nas produções. As análises empreendidas dialogam com os diagnósticos da escassa acumulação de conhecimento, a abundância de estudos setoriais e sem a verticalização desejada. Os resultados apontam dispersão temática, com estudos focados em políticas educacionais determinadas, sobretudo aquelas de períodos recentes. As principais fontes utilizadas pelos pós-graduandos foram os documentos oficiais sobre as ações dos governos e a legislação, especialmente a educacional.
\end{abstract}

Palavras-chave: Escolhas temáticas. Fontes de Pesquisa. Campo Acadêmico. Políticas Educacionais.

Research in Educational Policies: thematic choices and sources in debate (2000-2010)

\begin{abstract}
The study problematizes the characteristics of master's and doctoral research and their delineations regarding thematic choices and research's sources in the field of educational policies. In order to accomplish this, we use a database of theses and dissertations presented from 2000 to 2010 in Postgraduate Programs of Education in Brazil, organized by two research projects developed between 2012 and 2017, which allows the debate between empirical findings and analyzes of influential authors in the area, identified as those most mentioned in the productions. The analysis made dialogue with the diagnostics of the scarce accumulation of knowledge, the abundance of sectorial studies and without the desired verticalization. The results point to thematic dispersion, with studies focusing on specific educational policies, especially those of recent periods. The main sources used by post-graduate students were official documents on government actions and legislation, especially on education.
\end{abstract}

Keywords: Thematic choices. Academic field. Research'sources Educational Policies.

\footnotetext{
* A pesquisa foi financiada pelo CNPq.
} 
Investigación en Políticas Educacionales: escuelas temáticas y fuentes en debate (2000-2010)

Resumen: El estudio problematiza las características de las investigaciones de maestría y doctorado y sus delineamientos en cuanto a las elecciones temáticas ya las fuentes de investigación en el campo de las políticas educativas. Para ello, nos valemos de un banco de tesis y disertaciones defendidas en el período 2000 a 2010 en programas de postgrado en educación en Brasil, organizado por dos investigaciones desarrolladas entre 2012 y 2017, lo que permite el debate entre hallazgos empíricos y análisis de autores influyentes en el área, identificados como aquellos más referidos en las producciones. Los análisis emprendidos dialogan con los diagnósticos de la escasa acumulación de conocimiento, la abundancia de estudios sectoriales y sin la verticalización deseada. Los resultados apuntan dispersión temática, con estudios enfocados en políticas educativas determinadas, sobre todo aquellas de períodos recientes. Las principales fuentes utilizadas por los postgraduados fueron los documentos oficiales sobre las acciones de los gobiernos y la legislación, especialmente la educativa.

Palabras clave: Elecciones temáticas. Campo académico. Fuentes de investigación. Políticas Educativas.

\section{Introdução}

Desde o final da década de 1990, estudos como o de Melo (1999) e Souza (2006) têm ressaltado o caráter hodierno das políticas públicas como uma unidade de análise, bem como as influências distintas que vêm exercendo as escolas europeia e norte-americana, sobretudo no que concerne à sua institucionalização como um campo disciplinar e os desafios para a produção de conhecimentos dessa natureza. Nesse contexto, Melo (1999) assinala a distinção entre a produção no âmbito governamental e nas universidades, evidenciando a tensão entre a institucionalização da produção e uma militância anti-institucionalização que assegurou o contraponto crítico, com relativa autonomia frente às práticas de governos. A institucionalização do campo é descrita, pois, como "relativamente problemática e muito recente" (MELO, 1999, p. 63). No dizer do próprio Melo (1999, p. 63), "isso se explica fundamentalmente pelo caráter interdisciplinar da produção intelectual que é fator de fragmentação organizacional da comunidade científica”.

Associado a isso, o autor chama a atenção para os limites da institucionalização do campo e do seu objeto, dada a ausência de "um aparato material característico", o que se agrava quando se trata de identificar os protagonistas dessa produção, sobretudo nas relações entre especialistas setoriais em políticas e os pesquisadores de disciplinas específicas (educação, por exemplo). A despeito disso, a expansão da área ou das subáreas, na dimensão mais específica das disciplinas, é um fato reconhecido, sendo a criação de instituições e o incremento das produções elementos constitutivos desse processo. No Brasil, de acordo com Melo (1999, p. 66),

A área temática recoberta pelo que se passou a denominar análise de políticas públicas abrange um conjunto bastante heterogêneo de contribuições. Esse conjunto pode ser algo arbitrariamente desagregado em três subconjuntos de trabalhos. O primeiro subconjunto toma como objeto o regime político, instituições políticas ou o Estado brasileiro em termos de seus traços constitutivos, para investigar uma política específica. O segundo subconjunto de trabalhos engloba trabalhos sobre políticas setoriais que combinam a análise de processo político com a análise de problemáticas internas às próprias áreas setoriais. O terceiro subconjunto consiste nas análises de avaliação de políticas.

Especificamente quanto aos estudos de políticas educacionais no Brasil essa heterogeneidade se apresenta não só no que concerne aos objetos de estudo, mas aos seus usos e sentidos para uma agenda de interlocução da comunidade científica e entre esta e as questões educacionais. Para Libâneo (2008, p. 168), por exemplo, "há uma distância considerável entre as políticas educacionais, a legislação educacional, a pesquisa acadêmica e o que acontece na 
realidade das escolas, isto é, no ensino, no trabalho cotidiano dos professores, na aprendizagem dos alunos." Por essa via, o autor busca aproximações que passam pela problematização das políticas públicas em sua dupla dimensão de constructo social e constructo de pesquisa (MULLER; SUREL, 2002), o que envolve uma questão extremamente sensível no debate contemporâneo, sobretudo em razão de sua tendência pragmática de valorização da produção acadêmica pelos seus usos imediatos.

Paro (2001), por outro lado, questiona o tratamento fenomênico da realidade educacional, em detrimento das determinações mais amplas do real que envolvem o objeto. O autor destaca a importância de maior equilíbrio no tratamento da relação "micro/macro", no sentido de "não deixar de levar em conta a mútua determinação de ambos e, mais importante, não deixar de colocar no mesmo nível de importância a concretude do chamado 'micro', até porque, sem a apreensão dessa concretude, não é possível esclarecer aquela determinação.” (p. 32).

As preocupações trazidas por Libâneo (2008) e Paro (2001) remetem à complexidade do objeto numa linha muito próxima daquilo que Melo (1999) problematizou acerca das dificuldades da institucionalização do campo e da heterogeneidade da produção em políticas públicas.

Falando mais especificamente sobre pesquisa e produção de conhecimento em políticas educacionais, Krawczyk (2015, p. 9) põe em questão se no âmbito da compreensão do campo "estamos nos referindo à pesquisa em política educacional ou pesquisa das políticas educacionais?" (grifos nossos). A diferenciação se "em política ou das políticas" se apresenta para a autora nos seguintes termos:

No primeiro caso, reconhecemos que existe um campo específico de pesquisa que é a Política Educacional, com maiúsculas, e que precisa de diferentes aportes disciplinares. No segundo, estudamos diferentes políticas educacionais, seus propósitos e consequências. (KRAWCZYK, 2015, p. 9).

Tal diferenciação calha com as preocupações sobre a constituição do campo e se amplia à medida que colocamos em foco a análise das produções acadêmicas. Nessa direção, a autora chama atenção para os riscos da burocratização do trabalho científico, principalmente, em razão da forte associação entre atividade de formação (ensino) e produção de conhecimento. Em sua interpretação, "a maioria dos estudos tem focado o estudo de políticas educacionais determinadas. São poucos os que estudam a dinâmica política da produção de políticas como um espaço de atividade, de relações de poder, de conflitos, etc." (KRAWCZYK, 2015, p. 9, grifos nossos).

Nota-se que as análises trazidas pelos autores citados ilustram algumas das preocupações correntes entre os pesquisadores de educação no enfoque das políticas públicas. Considerando, pois, a produção intelectual de pesquisadores em formação nos programas de pós-graduação em educação, este artigo mapeia e analisa as escolhas temáticas e as fontes de pesquisa que deram suporte aos estudos em políticas educacionais, tomando como base empírica teses e dissertações defendidas entre 2000 e 2010. Devido ao número de programas de pós-graduação na área (em 2012, ano de início da coleta de dados, eram 144 programas) e os limites operacionais para trabalhar com esse universo, decidiu-se pela composição do corpus da pesquisa pelos programas com os escores mais elevados na avaliação da Coordenação de Aperfeiçoamento de Pessoal de Nível Superior (CAPES), considerando a condição de programas mais consolidados e com o curso de doutorado. Dessa forma, foram selecionados os programas que tiveram as notas cinco, seis e sete na avaliação trienal encerrada em 2010. Em razão do critério da nota foram mapeadas as produções dos programas das seguintes instituições: Pontifícia Universidade Católica de São Paulo (PUC-SP), Pontifícia Universidade Católica do Rio de Janeiro (PUC-RJ), Pontifícia 
Universidade Católica do Rio Grande do Sul (PUC-RS), Universidade de São Paulo (USP), Universidade do Vale do Rio dos Sinos (Unisinos), Universidade Estadual de Campinas (Unicamp), Universidade Estadual do Rio de Janeiro (Uerj), Universidade Estadual Paulista "Júlio de Mesquita Filho" campus Marília (Unesp-Marília), Universidade Federal de Goiás (UFG), Universidade Federal de Minas Gerais (UFMG), Universidade Federal de Pelotas (Ufpel), Universidade Federal de São Carlos (Ufscar), Universidade Federal de Uberlândia (UFU), Universidade Federal do Espírito Santo (Ufes), Universidade Federal do Paraná (UFPR), Universidade Federal do Rio de Janeiro (UFRJ), Universidade Federal do Rio Grande do Norte (UFRN), Universidade Federal do Rio Grande do Sul (UFRGS), Universidade Federal Fluminense (UFF), Universidade Metodista de Piracicaba (Unimep).

Como veremos a seguir, o estudo de políticas educacionais determinadas ainda prevalece entre as pesquisas selecionadas, indicando a importância de pautarmos esse tipo de preferência e suas implicações para a área.

Nesse contexto, a caracterização das escolhas temáticas e a problematização das fontes são confrontadas às análises em voga pelos autores mais referidos nas produções, aqui identificados como autores influentes. Tello e Mainardes (2012) chamaram esses autores de "investigador-referente".

\section{Escolhas temáticas e fontes nos estudos de políticas educacionais}

Pelo critério da nota dos programas, conforme já assinalado, foram selecionadas 20 instituições e 21 programas (na Ufscar foram selecionados dois programas). Ao todo foram catalogados 1.283 trabalhos provenientes de 20 programas, posto que no programa de pósgraduação da PUC-SP não foram encontrados trabalhos relacionados com políticas educacionais. Os dados reunidos revelaram que houve grande incremento da produção de teses e dissertações entre os programas de pós-graduação selecionados no decênio 2000-2010 e os doutorados, proporcionalmente, foram os que cresceram mais. Assim, do total de 851 dissertações e 432 teses catalogadas, apurou-se taxas aproximadas de crescimento de $212 \%$ e $462 \%$, respectivamente (BELLO, JACOMINI, MINHOTO, 2016), como se pode verificar no Quadro 01. 
Quadro 1 - Instituições (IES) por Região, conceito em 2010 e número de trabalhos 2000-2010

\begin{tabular}{|c|c|c|c|c|c|c|c|}
\hline \multirow{2}{*}{ Ord. } & \multirow{2}{*}{ IES } & \multirow{2}{*}{ Região } & \multicolumn{2}{|c|}{ Ano de Implantação } & \multirow{2}{*}{ Conceito } & \multicolumn{2}{|c|}{$\mathrm{N}^{o}$ de trabalhos } \\
\hline & & & Mestrado & Doutorado & & $\mathrm{M}$ & $\mathrm{D}$ \\
\hline 1 & PUC-RIO & Sudeste & 1965 & 1976 & 7 & 45 & 32 \\
\hline 2 & UERJ & Sudeste & 1979 & 2002 & 7 & 75 & 22 \\
\hline 3 & UFMG & Sudeste & 1972 & 1991 & 7 & 50 & 18 \\
\hline 4 & $\mathrm{PUC} / \mathrm{RS}$ & Sul & 1972 & 1989 & 6 & 5 & 6 \\
\hline 5 & UFF & Sudeste & 1971 & 1995 & 6 & 32 & 12 \\
\hline 6 & UFSCAR & Sudeste & 1978 & 1999 & 6 & 45 & 19 \\
\hline 7 & UNISINOS & Sul & 1994 & 1999 & 6 & 57 & 34 \\
\hline 8 & USP & Sudeste & 1971 & 1978 & 6 & 44 & 51 \\
\hline 9 & $\mathrm{PUC} / \mathrm{SP}$ & Sudeste & 1969 & 1982 & 5 & - & - \\
\hline 10 & UFES & Sudeste & 1978 & 2004 & 5 & 33 & 1 \\
\hline 11 & UFG & $\begin{array}{l}\text { Centro- } \\
\text { Oeste }\end{array}$ & 1986 & 2001 & 5 & 49 & 9 \\
\hline 12 & UFPEL & Sul & 1995 & 2006 & 5 & 6 & 1 \\
\hline 13 & UFPR & Sul & 1976 & 2001 & 5 & 65 & 8 \\
\hline 14 & UFRGS & Sul & 1972 & 1976 & 5 & 64 & 49 \\
\hline 15 & UFRJ & Sudeste & 1972 & 1980 & 5 & 28 & 14 \\
\hline 16 & UFRN & Nordeste & 1978 & 1994 & 5 & 27 & 19 \\
\hline 17 & UFSCAR & Sudeste & 1976 & 1991 & 5 & - & - \\
\hline 18 & UFU & Sudeste & 1989 & 2006 & 5 & 48 & 4 \\
\hline 19 & UNESP/MAR & Sudeste & 1988 & 1993 & 5 & 25 & 20 \\
\hline 20 & UNICAMP & Sudeste & 1975 & 1980 & 5 & 104 & 91 \\
\hline 21 & UNIMEP & Sudeste & 1972 & 1992 & 5 & 49 & 22 \\
\hline
\end{tabular}

Fonte: Planilhas Comparativas de Avaliação Trienal /Capes /2010 (BRASIL, 2010); Bello, Jacomini e Minhoto (2016).

OBS.: Não houve separação dos trabalhos coletados em cada programa da UFscar, assim embora na tabela conste separadamente os dois programas, com respectivas notas, o conjunto de trabalhos desta Instituição foram colocados na linha seis, embora corresponda à totalidade dos dois programas.

Considerou-se para a coleta somente os trabalhos relacionados com políticas educacionais, articulando três critérios de seleção disponíveis para busca no banco de teses da CAPES: ano, instituição e palavras-chave (descritores previamente estabelecidos). As palavraschave derivaram dos nove eixos que guiaram a classificação dos trabalhos, a saber: Eixo 1 Organização da educação, planejamento da educação, administração da educação, gestão da educação; Eixo 2 - Avaliação em larga escala e avaliação institucional; Eixo 3 - Qualidade da educação, qualidade de ensino; Eixo 4 - Estado e Reformas educacionais; Eixo 5 - Políticas de Formação de professor, carreira docente; Eixo 6 - Financiamento da educação; Eixo 7 Abordagens teórico-metodológicas; Eixo 8 - Análise e avaliação de Programas e projetos; Eixo 9 - Políticas inclusivas (SILVA; JACOMINI, 2016a).

Os trabalhos coletados nessas instituições foram organizados em um banco de dados que publiciza as características básicas das teses e dissertações: autor, orientador, instituição, linha de pesquisa, ano de defesa, resumo, país, região, estado e cidade que são objeto de estudos, dentre outros aspectos, observando sempre as declarações constantes nos textos recolhidos no site da CAPES. Quando da identificação das temáticas, porém, verificou-se uma lista muito ampla de 
possibilidades e isto conduziu à composição de um quadro de temáticas arbitrado pelas autoras deste artigo, com base no estudo dos resumos do total das teses e dissertações mapeadas. Apesar disso, considerou-se o que os autores declararam como o foco ou tema, assim como a proximidade ou interface do conteúdo com algumas categorias correntes nos estudos em políticas educacionais, mesmo reconhecendo que há limites em toda tentativa de enquadramento. A abrangência das correlações estabelecidas pelos autores, portanto, levou-nos ao exercício de agrupar os trabalhos pela combinação entre o que estava anunciado, explicitamente, no resumo como universo global (categoria mais abrangente, como financiamento) e a sua síntese (categoria de singularização do trabalho), aqui denominado como tema correlato. A título de exemplo podese citar os estudos na temática de avaliação e os recortes que lhe dão singularidade, como avaliação de sistemas e institucional na coluna de temas correlatos (Quadro 2).

Ao todo foram identificadas 50 temáticas, das quais derivam temas correlatos que traduzem a problematização de nuanças, singulares, conforme discriminamos nos Quadros 2 a 4, embora também se constate temáticas que não tiveram temas correlatos, conforme indica o Quadro 5. Em atenção ao que os autores dos trabalhos registraram em seus resumos é possível identificar casos em que os temas correlatos podem figurar como temáticas.

No Quadro 2, são apresentadas as quatro temáticas com 10 ou mais temas correlatos, os quais são separados por ponto e vírgula, a barra informa as interfaces que se apresentam no interior dos temas correlatos. A organização da temática mais ampla e a indicação dos temas correlatos permitem perceber as possibilidades de enfoques explorados pelos pós-graduandos, alguns dos quais com nuanças pouco visíveis nos debates correntes. 
Quadro 2 - Temáticas em teses e dissertações 2000-2010, com 10 ou mais temas correlatos

\begin{tabular}{|c|c|}
\hline TEMÁTICAS & TEMAS CORRELATOS \\
\hline Análise de Políticas & $\begin{array}{l}\text { Políticas Governamentais } \\
\text { alfabetização/formação do leitor; carreiras; espaços } \\
\text { escolares /infraestrutura; gerencialismo/empresários; } \\
\text { gestão de sistema; história; ideologia; público-privado; } \\
\text { visões dos profissionais sobre as políticas } \\
\text { governamentais; Análise de Políticas Internacionais (a } \\
\text { maioria explorando relações com políticas } \\
\text { implementadas no Brasil): alfabetização e formação } \\
\text { de leitor; Brasil/Mercosul; formação de professores; } \\
\text { gestão de sistemas; intercâmbios/ parcerias. }\end{array}$ \\
\hline Avaliação & $\begin{array}{l}\text { Avaliação de Sistema (Enem, gestão de sistema, Proeb, } \\
\text { Saeb, Saresp, Saresp/ impactos nos alunos negros); } \\
\text { Avaliação Institucional (aprendizagem, gestão da } \\
\text { escola); Indicadores de qualidade; Educação Superior; } \\
\text { Escola/Ideb; Pós-graduação; Qualidade/produção da } \\
\text { RBEP; Políticas internacionais; Proficiência em larga } \\
\text { escala. }\end{array}$ \\
\hline Educação Superior & $\begin{array}{l}\text { Educação Superior: Ações Afirmativas; Autonomia; } \\
\text { Avaliação de políticas internacionais, Carreiras; } \\
\text { Currículo; Docência; Expansão, Financiamento; } \\
\text { Formação Docente; Gestão; Privatização, Público- } \\
\text { privado; Qualidade; Reforma. }\end{array}$ \\
\hline Gestão & $\begin{array}{l}\text { Gestão da Escola: colegiados escolares, família, } \\
\text { formação no curso de pedagogia, inclusão, liderança } \\
\text { pedagógica, TICs; Sistema (atuação de governos, } \\
\text { conselho de escola, formação de conselheiros, gestão da } \\
\text { escola, participação); Gênero; Conselho de Educação; } \\
\text { Conselho de Escola e PPP; Conselho } \\
\text { Escolar/participação; Áreas de transição; Concepções; } \\
\text { Conselho Municipal; Conselhos de Escola; Constituição } \\
\text { da área de administração; Descentralização e/ou } \\
\text { democratização; EJA, Família; Federalismo; Formação } \\
\text { de gestores; Movimento sindical; Orçamento } \\
\text { Participativo; Participação; Plano de Desenvolvimento } \\
\text { Educacional; Planos de Educação, Projeto Pedagógico; } \\
\text { Qualidade total; Autonomia da escola; Administração da } \\
\text { educação, Teoria da administração escolar. }\end{array}$ \\
\hline
\end{tabular}

Fonte: Elaboração própria, com base em Silva et al. (2014).

A grande quantidade de temas correlatos (que indicam o enfoque dado pelo autor) sugere que no universo das linhas de pesquisas dos programas de pós-graduação há uma multiplicidade de objetos que são estudados pelos pós-graduandos, nem sempre em articulação direta com os projetos de pesquisas dos orientadores. Tal prática revela a preservação de certa autonomia discente na proposição dos seus objetos de estudo, embora também concorra para a dissipação de esforços para a acumulação de conhecimentos em torno de temáticas estratégicas.

No Quadro 3, estão situadas as seis temáticas que tiveram entre cinco e nove temas correlatos nos estudos dos pós-graduandos. Observamos neste grupo uma pulverização das correlações exploradas. 
Quadro 3 - Temáticas com cinco a nove temas correlatos nas teses e dissertações 2000-2010

\begin{tabular}{|c|c|}
\hline TEMÁTICAS & TEMAS CORRELATOS \\
\hline Financiamento & $\begin{array}{l}\text { Estudantil/custo aluno; Externo; Debate internacional; } \\
\text { Autonomia financeira/gastos públicos; Controle } \\
\text { social/orçamento participativo; Desempenho escolar; } \\
\text { Políticas de fundos. }\end{array}$ \\
\hline Fluxo Escolar & $\begin{array}{l}\text { Evasão; Fracasso; História, permanência; Recuperação; } \\
\text { Repetência; Sucesso. }\end{array}$ \\
\hline Políticas de Formação de Professor & $\begin{array}{l}\text { Progressão; História; identidade; Inclusão; Relações } \\
\text { étnico-raciais; Profissional/estágio; Continuada; Políticas } \\
\text { educacionais e práticas docentes. }\end{array}$ \\
\hline Organização do Ensino em Ciclos & $\begin{array}{l}\text { Avaliação da aprendizagem; Organização do trabalho } \\
\text { pedagógico; Progressão continuada; Reformas } \\
\text { educacionais; Tempos escolares. }\end{array}$ \\
\hline Inclusão & $\begin{array}{l}\text { Diagnóstico e acompanhamento; Docência; Gestão da } \\
\text { escola; História; Linguagens; Políticas discursivas; } \\
\text { Projeto Político Pedagógico (PPP). }\end{array}$ \\
\hline Políticas de Currículo & $\begin{array}{lccr}\text { Concurso } & \text { vestibular; } & \text { Docência; } & \text { Espaços } \\
\text { escolares/infraestrutura; } & \text { Estudantes, } & \text { Formação } \\
\text { profissional; } & \text { Relações } & \text { étnico-raciais; } & \text { Reorientação } \\
\text { curricular. }\end{array}$ \\
\hline
\end{tabular}

Fonte: Elaboração própria, com base em Silva et al. (2014).

As temáticas de financiamento, fluxo escolar, políticas de formação de professores, organização do ensino em ciclos, inclusão e políticas de currículo também foram investigadas, sob diferentes aspectos. Correlacionada à temática "Políticas de Currículo", por exemplo, foram desenvolvidas pesquisas com foco nos concursos vestibulares, relações étnico-raciais, reorientação curricular etc, denotando a diversidade dos enfoques, o que, em certa medida, contribui para uma compreensão mais abrangente das temáticas.

No Quadro 4, diferentemente dos anteriores, consta um conjunto de 22 temáticas com poucos temas correlatos, isto é, que alcançaram até quatro possibilidades de enfoques específicos. 
Quadro 4 - Temáticas com até quatro temas correlatos em teses e dissertações 2000-2010

\begin{tabular}{|c|c|}
\hline Temáticas & Temas correlatos \\
\hline Movimentos Sociais & $\begin{array}{l}\text { Relações étnico-raciais/ações afirmativas; } \\
\text { Gênero/homofobia; Gestão }\end{array}$ \\
\hline Ações Afirmativas & Desempenho escolar; Educação pública/contexto social \\
\hline Organizações Não Governamentais & Combate à pobreza; Formação/gestão \\
\hline Planejamento & $\begin{array}{l}\text { Plano de Desenvolvimento da Educação/gestão; Planos } \\
\text { para Educação }\end{array}$ \\
\hline Adolescente & $\begin{array}{l}\text { Conflito com a lei; Infrator/fluxo escolar; } \\
\text { Criança/organizações sociais; Criança/direitos }\end{array}$ \\
\hline Pós-Graduação & Docência/produção; História; Pesquisa compartilhada \\
\hline Projeto Político-Pedagógico & $\begin{array}{l}\text { Desempenho escolar no ensino noturno; projetos } \\
\text { culturais }\end{array}$ \\
\hline Trabalho Docente & Identidade; Trabalho e Educação; Saber docente \\
\hline Qualidade da Educação & Docência e qualidade do ensino \\
\hline Acesso à Educação & Democratização; Qualidade \\
\hline Direito à Educação & Cidadania; Direitos humanos \\
\hline Educação a Distância & Formação de professores; História \\
\hline Educação no Campo & Gestão; História \\
\hline Educação de Jovens e Adultos & Desempenho; Gestão \\
\hline Ensino Fundamental & Ensino fundamental de nove anos \\
\hline Ensino Médio & Reforma \\
\hline Escola de Tempo Integral & Tempo escolar \\
\hline Estado e Educação & Reforma educacional \\
\hline Federalismo & Financiamento \\
\hline Juventude & Violência \\
\hline Municipalização & Gestão de sistema \\
\hline Tecnologia da Informação e Comunicação & Gestão \\
\hline
\end{tabular}

Fonte: Elaboração própria, com base em Silva et al. (2014).

É interessante observar que a temática da gestão que aparece no Quadro 2 com muitos temas correlatos, no Quadro 4 ela é tema correlato das temáticas Movimentos Sociais, Organizações Não-Governamentais, Educação no Campo, Educação de Jovens e Adultos, Municipalização e Tecnologia da Informação e Comunicação. O mesmo ocorre com financiamento que no Quadro 3 aparece como temática com sete temas correlatos, no Quadro 4 ele é tema correlato da temática Federalismo. Nota-se também nos quadros 2, 3 e 4 que há temas correlatos que são bastante frequentes nos estudos de políticas educacionais, a exemplo de Ações Afirmativas, Formação de Professores e de Financiamento.

Demarcando de forma mais explícita a tendência à pulverização das temáticas, o Quadro 5 aponta um total de 18 delas que não apresentaram temas correlatos. 
Quadro 5 - Temáticas em teses e dissertações 2000-2010

\begin{tabular}{|l|}
\hline \multicolumn{1}{|c|}{ Temáticas } \\
\hline Assistência Social/ Amparo Pedagógico \\
\hline Classes Hospitalares \\
\hline Cooperativa/cooperativismo \\
\hline Diversidade/Culturas e Identidades \\
\hline Educação Ambiental \\
\hline Educação em Penitenciárias \\
\hline Educação Sexual \\
\hline Empresa/Empresários e Educação \\
\hline Ensino Noturno \\
\hline Escola Pública/Formação da Vontade Geral \\
\hline Intelectuais/Influência no Pensamento Pedagógico \\
\hline Interdisciplinaridade \\
\hline Movimento Sindical \\
\hline Organização de Sistemas \\
\hline Organizações Sociais \\
\hline Produção e Circulação de Saberes \\
\hline Quase Mercado \\
\hline
\end{tabular}

Fonte: Elaboração própria, com base em Silva et al. (2014).

A análise das produções revela que os estudos têm sido abordados no marco da ideologia neoliberal e dos seus desdobramentos por meio da Reforma do Estado. Ainda que apoiadas em referenciais de matrizes epistemológicas variadas, tendem a dar mais atenção aos estudos dos espaços mais próximos, indicando mudanças em relação à predominância de estudos sobre políticas públicas nacionais, conforme indicado por Azevedo e Aguiar (2001), em relação à década de 1990. Combinado a isso, observa-se a produção de dados localizados e pouco conectados às pesquisas em rede, o que favorece à fragmentação dos esforços e ao isolamento dos grupos de pesquisas, desde os programas de pós-graduação.

A despeito da instituição das linhas de pesquisas e a busca de delineamentos que melhor harmonizassem a relação linhas de pesquisa-orientador-estudantes de pós-graduação, nota-se que a aderência entre esses componentes ainda é fluída. Assim, os objetos de estudo dos estudantes nem sempre se apresentam como subprojetos ou temas diretamente vinculadas às produções de seus orientadores, indicando a sobrevivência de relações acadêmicas em que os estudantes guardam certa autonomia na escolha de seus temas ${ }^{1}$. Esta dinâmica, se por um lado contribui para a diversificação dos objetos, por outro não corrobora para a verticalização das pesquisas, por meio do desenvolvimento de projetos em redes, o que potencializaria o aprofundamento dos conhecimentos a partir da análise das prioridades da área, assim como dos diagnósticos sobre as condições para a produção do conhecimento.

Como já relatado em estudos anteriores, os dados demonstraram que os referenciais utilizados pelos pesquisadores são difusos e nem sempre explicitados. Entre os 1283 trabalhos

\footnotetext{
${ }^{1}$ Encontram-se orientadores com interesses de pesquisas mais implicados com Filosofia da Educação, orientando trabalho sobre política educativa em Angola, por exemplo.
} 
[...] menos de um terço faz menção ao referencial teórico utilizado e, entre estes, nem sempre se explicita relação entre a indicação de autor e sua vinculação às abordagens epistemológicas. Estas, enquanto campo de disputas teórico-metodológicas, para além do autor em si, informam as rupturas e/ou pertencimentos conceituais político-sociais. (SILVA; JACOMINI, 2016b, p. 106).

Dentre os estudos que explicitaram o referencial, constatou-se um repertório bibliográfico diversificado, evidenciando o uso de autores de orientações epistemológicas variadas e oriundos de áreas de conhecimento igualmente diversas, a exemplo de Filosofia, História, Ciências Sociais, Administração, Ciência Política.

Desse modo, poucos são os autores que aparecem como referência em um número maior de trabalhos e, portanto, são percebidos como autores influentes na área, com presença marcante nos estudos. Entre estas exceções, destacaram-se na literatura estrangeira, especialmente da Europa, os nomes de Antonio Gramsci, Stephen J. Ball, António Nóvoa, Boaventura de Souza Santos, Pierre Bourdieu, Theodor Adorno, Thomas Popkewit, Michael de Certeau, Basil Bernstein. Fora da fronteira europeia destacaram-se as referências a Maurice Tardif (Canadá) e aos brasileiros Paulo Freire, Luiz Antônio Cunha e Carlos Roberto Jamil Cury. A grande maioria dos autores referidos, no entanto, não logrou uma frequência constante entre os trabalhos. Essa dispersão se apresentou como um elemento dificultador de qualquer tentativa de identificar autores com influência dominante num número expressivo de trabalhos ${ }^{2}$. Deste modo, a presença do "investigador referente", no sentido atribuído por Tello e Mainardes (2012) revelouse tênue como característica das produções em questão.

A diversificação das abordagens e sua heterogeneidade vão ao encontro de interpretações como a de Azevedo (1997), que questiona a "rigidez de determinadas categorias préestabelecidas" (p. 58) e sai em defesa dos espaços de interseções teóricas por meio de alinhamentos teórico-metodológico que possam explorar referenciais mais heterodoxos. Assim, de par com as análises sobre a natureza híbrida dos estudos em educação e em políticas públicas, nota-se que as pesquisas aqui caracterizadas também foram apoiadas nas interfaces entre distintas disciplinas, com ênfases que revelam mais dispersão do que afluência dos referenciais. Tal característica não chega a ser uma novidade. Ademais, nas palavras de Lessard (2011) as Ciências Humanas e Sociais (CHS),

São caracterizadas pela diversidade dos paradigmas, das epistemologias e das metodologias, assim como pela coexistência mais ou menos tensa entre essas diferentes abordagens; a "normalidade" nas CHS é sobretudo desta natureza e não tanto no predomínio de um paradigma. Sua evolução é menos marcada por revoluções paradigmáticas sucessivas do que por deslocamentos de ênfase [...] ou por uma busca de equilíbrio entre abordagens sistêmicas e procedimentos focalizados nas lógicas de ator, ou metodologias híbridas. (LESSARD, 2011, p. $629)$.

No que toca às teses e dissertações analisadas, as escolhas temáticas ainda são fortemente marcadas pelos estudos de políticas setoriais, evidenciando a permanência de uma tendência já conotada em outros estudos, conforme assinalado (SILVA; JACOMINI 2016b). Sobre as motivações para tais escolhas, foi frequente a relação estabelecida com as experiências mais imediatas dos mestrandos e doutorandos, o que os tornou sensíveis a temas contemporâneos e relacionados a seus universos de trabalho. Nesse contexto, a produção acadêmica revela-se tão dispersa quanto heterogênea, com pouca atenção aos estudos sobre a constituição do campo, em

\footnotetext{
${ }^{2}$ Os autores mais citados foram referidos em cinco ou mais trabalhos.
} 
paralelo à intensificação de estudos voltados ao Estado e às reformas educacionais, organização da educação (planejamento, gestão), formação de professores, bem como análise e avaliação de programas e projetos (SILVA; JACOMINI, 2016b). A análise de políticas governamentais, tornou-se, pois, o carro chefe das produções, abrangendo temáticas bem variadas, mas, via de regra abarcando análises sobre concepção das políticas, implementação e apreensão dos seus resultados.

Em relação à implementação de políticas foram identificados 33 resumos que fizeram referências a esse enfoque de forma mais direta e outros 195 em que a palavra implementação vem acompanhada de projetos e programas, indicando importante presença de estudos sobre implementação de políticas, cabendo a estudos futuros a análise das características dessas pesquisas no referido banco de dados.

Em alguns estudos não há diferenciação entre políticas públicas e programas, tomandoos um pelo outro. Tal indiferenciação também alcança a legislação, a qual é tomada como política e, algumas vezes, como referência. Essas situações denotam a simplificação da noção de políticas públicas como fato isolado, minimizando-a como série de comportamentos que envolvem sujeitos e movimentos diversos. De acordo com Palumbo (1998), a análise de políticas públicas não deve ficar restrita à "política" específica ou programa que se toma como objeto de estudo, é preciso compreendê-la como parte de um movimento mais amplo, posto que "cada decisão é um evento em uma sequência de eventos que determinam uma política ao longo do tempo" (p. 37). Assim, um programa pode ser compreendido como um meio específico para colocar uma política em prática, sendo necessário para melhor entendê-lo considerar os diversos movimentos que ocorrem num tempo maior que aquele que o circunscreve.

Entendendo que os cuidados com as fontes são parte essencial do trabalho do pesquisador, em qualquer área do saber, nos parece que maior atenção a esse arcabouço é parte importante dos movimentos de fortalecimento dos estudos em políticas educacionais. As fontes, no dizer de Cellard (2008), são para os historiadores,

os depoimentos de contemporâneos do acontecimento que eles desejam reconstituir. Distinguem-se, geralmente, as fontes "primárias", produzidas por testemunhas diretas do fato, das fontes "secundárias", que provêm de pessoas que não participaram dele, mas que o reproduziram posteriormente. (CELLARD, 2008, p. 297).

Em políticas educacionais poderíamos dizer que as fontes abarcam peças e sujeitos variados de onde se possa extrair informações que exprimam práticas, conceitos, valores e relações entre pessoas, instituições e os tempos passado, presente e futuro, considerando que alguns documentos referem-se a planos que prospectam o futuro.

Nos estudos mapeados pela pesquisa, as abordagens qualitativas são predominantes e os estudos documentais estão entre os que mais se destacam. Não obstante, as fontes referidas nas teses e dissertações não variam tanto quanto às temáticas e podem ser agrupadas em quatro subconjuntos: a) documentais (impressos, leis, relatórios, programas, projetos, dentre outros); b) bibliográficas; c) relatos ou depoimentos orais (entrevistas e grupos focais); d) registros livres ou sistemáticos (observações in loco).

Os documentos escritos, como indica Cellard (2008) abrangem muitas possibilidades, mas, grosso modo, podem-se repartir entre os "arquivados e os que não o são", mas faz muita diferença estabelecer o status dos documentos quanto ao seu domínio público ou privado. Os documentos públicos, abrangem: 
- Os arquivos públicos. Trata-se de uma documentação geralmente volumosa e, por vezes, organizada segundo planos de classificação, complexos e variáveis no tempo. Ainda que ela seja dita pública, ela nem sempre é acessível. Esse tipo de arquivo compreende comumente: os arquivos do estado civil, assim como alguns arquivos de natureza notorial ou jurídica.

- Os documentos públicos não-arquivados. Eles incluem, entre outros, os jornais, revistas, periódicos e qualquer outro tipo de documentos distribuídos: publicidade, anúncios, tratados, circulares, boletins paroquiais, anuários telefônicos, etc. (CELLARD, 2008, p. 297).

Já os documentos privados são designados pelo autor da seguinte forma:

- Os arquivos privados. Ainda que ela não pertença ao domínio público, ocorre que uma documentação de natureza privada seja arquivada. Ela pode, contudo, ser de acesso bastante difícil. Trata-se aqui, principalmente, de documentos de organizações políticas, sindicatos, Igrejas, comunidades religiosas, instituições, empresas, etc.

- Os documentos pessoais. Esta categoria reúne autobiografias, diários íntimos, correspondências, histórias de vida, documentos de família, etc. (CELLARD, 2008, p. 297).

No que pese à abrangência das possibilidades de documentos como fontes, identificamos que, entre as teses e dissertações que compuseram o corpus dos nossos estudos, os documentos oficiais que informam as ações de governo e a legislação foram os mais utilizados, sobretudo aqueles não arquivados e que estão disponibilizados nos sites públicos. Isto, se por um lado denota a importância dos meios virtuais na difusão e facilitação do acesso, por outro, revela que não é corrente entre nós a prática de acessar os arquivos públicos, conforme a caracterização de Cellard (2008), especialmente os de natureza notarial ou jurídica. Estes são citados pelo autor como os mais difíceis de acessar, mas no caso dos estudos em políticas educacionais eles não vêm tendo maiores repercussões nas pesquisas em questão, posto que são poucos os que buscam esse tipo de fonte. Entre os poucos exemplos de uso deste tipo de fonte, destacamos uma pesquisa que analisou a revista "A defesa Nacional", no período de 1913 a 1970. O autor estuda a influência da Escola Superior de Guerra no campo educacional, especialmente em relação aos pressupostos positivistas que culminaram na introdução da disciplina "Educação Moral e Cívica" nos currículos das escolas (SEPULVEDA, 2010).

Entre as fontes relacionadas aos documentos públicos não-arquivados os periódicos têm presença relevante nos estudos do tipo estado do conhecimento ou estado da arte. Já os jornais, incluindo os do tipo "diário oficial", ainda ocupam lugar secundário, via de regra, como base auxiliar. Os intelectuais que lidam com a matéria das políticas públicas de educação, portanto, parecem não dar tanta atenção a esses veículos como fontes que traduzem as relações de poder e cumprem funções político-sociais não só pela tradução de suas visões, mas pelo recorrente apelo à condição de sujeitos imparciais. A esse respeito, é representativa a reflexão trazida por Vieira (2007) ao problematizar o jornal como uma fonte rica para investigações e que, no nosso entender, dialoga com relevantes questões para os estudos em políticas educacionais. Diz o autor: 
Desmontando o mito da imparcialidade, deparamos com as razões e os procedimentos dos agentes sociais na defesa de projetos, sejam eles econômicos, políticos ou culturais. Nessa direção analítica, o jornal pode ser representado pela metáfora do espelho que reflete a realidade, desde que entendamos, assim como a física explica, que refletir envolve distorção e refração. Nesse enfoque, cabe ao intérprete estudar o funcionamento desse sistema de espelhamento que discursivamente confere sentidos às coisas, às ações, às palavras ditas e não ditas. O jornal - entendido como lugar de produção, veiculação e circulação dos discursos - assume uma função importante no processo de formação das representações sobre o mundo. A produção da matéria jornalística, apoiada em processos conscientes e/ou inconscientes de seleção do que deve ser considerado notícia, tem a força de tornar coisas visíveis ou invisíveis, de criar efeitos de verdade e de objetividade sobre mitos e/ou de conferir plausibilidade a posições absurdas. Esse lugar de luzes e de sombras precisa ser interpretado, de tal maneira que seja possível ver o que foi olvidado e ressignificar o que se pretendia óbvio e indiscutível. Essa forma de leitura é possível quando compreendemos os enunciados presentes no impresso como intervenções de um agente social interessado em orientar formas de pensar, de sentir e de agir. (VIEIRA, 2007, p. 16).

Esse conjunto de elementos apresentados pelo autor, no nosso entender compreendem práticas essenciais ao pesquisador em políticas educacionais, sobretudo pelo apelo ao cultivo de posturas interpelativas às fontes, ao invés da sua mera descrição.

Ainda em relação às fontes, observamos um uso reduzido dos dados educacionais disponibilizados pelo Instituto Nacional de Estudos e Pesquisas Educacionais Anísio Teixeira (Inep), seja os do censo escolar já consolidados ou os microdados que permitem a extração de dados diversos daqueles que compõem as estatísticas do órgão.

\section{Considerações finais}

Este artigo colocou em relevo as escolhas temáticas e as fontes de pesquisa que dão suporte aos estudos em políticas educacionais, tomando como base empírica teses e dissertações defendidas entre 2000 e 2010, em 20 programas de pós-graduação que lograram conceito cinco ou mais na trienal da Coordenação de Aperfeiçoamento de Pessoal de Nível Superior (CAPES) concluída em 2010. Por meio dos dados reunidos foi possível evidenciar que as temáticas dos estudos abrangem um amplo repertório, reveladoras de certa autonomia dos pós-graduandos na proposição dos seus objetos de estudo. Pode-se supor que a partir de temáticas de pesquisa dos orientadores, os mestrandos e doutorandos escolheram aspectos específicos para desenvolverem seus estudos, contribuindo, em certa medida para adensar temas variados de pesquisa que são característicos do campo das políticas educacionais. Mas, conforme visto nos Quadro 4 e 5, há também um conjunto de temas que não estão diretamente vinculados às temáticas gerais mais comuns no campo, indicando uma diversidade salutar.

Ao lado da diversificação dos temas, constatou-se, também, a heterogeneidade e o caráter difuso dos referenciais adotados, muitos dos quais oriundos de áreas de conhecimento fronteiriças, com ênfases que revelam mais dispersão do que afluências constantes de autores e categorias de análises. Tal constatação indica que a "rigidez de determinadas categorias préestabelecidas", questionada por Azevedo (1997, p. 58), não se destaca entre os estudos selecionados, os quais traduzem mais interseções teóricas. Resta, contudo, avançar na análise dessas características e elucidar suas repercussões para o campo, sobretudo no sentido de uma possível diferenciação quanto às práticas de ecletismo nas pesquisas, o que demanda estudos de 
revisão do tipo metapesquisa, que permitiria identificar a perspectiva e o posicionamento epistemológicos, o enfoque epistemetodológico, o tipo de pesquisa e os marcos teóricos, conforme Tello e Mainardes (2015).

No que diz respeito às fontes de pesquisa, observou-se que não há tanta variação quanto às temáticas. Os documentos oficiais que informam as ações de governo e a legislação foram as fontes mais utilizadas. Também em relação às fontes de pesquisas, estudos de revisão que analisam os textos na íntegra poderão contribuir para um melhor conhecimento de seus usos pelos pesquisadores.

\section{Referências}

AZEVEDO, J. M. L. de. A educação como política pública. Campinas, SP: Autores Associados, 1997.

AZEVEDO, J. M. L.; AGUIAR, M. A. da S. Políticas de educação: concepções e programas. In: WITTMANN, L. C.; GRACINDO, R. V. (Orgs.). O estado da arte em política e gestão da educação no Brasil (1991-1997). Campinas: Autores Associados, 2001, p. 71-108.

BELLO, I. M; JACOMINI, M. A.; MINHOTO, M. A. P. Produção acadêmica em política educacional no Brasil: análises de teses e dissertações (2000-2010). In: SILVA, A. A; JACOMINI, M. A. (Orgs.). Políticas em políticas educacionais: características e tendências. Feira de Santana: UEFS Editora, 2016. p. 63-92

BRASIL. Coordenação de Aperfeiçoamento de Pessoal de Nível Superior (CAPES). Planilhas comparativas de avaliação trienal /CAPES /2010. Brasília, DF: CAPES, 2010. Disponível em:< www.capes.gov.br $>$. Acesso em: 17 e 18 maio 2011.

CELLARD, A. A análise documental. IN: POUPART, J. et al. (Orgs.). Pesquisa qualitativa: enfoques epistemológicos e metodológicos. Petrópolis: Vozes, 2008.

KRAWCZYK, N. Pesquisa e formação em política educacional: um desafio interdisciplinar. Olhares, Guarulhos, v. 3, n. 2, p. 8-14, nov. 2015.

LESSARD, C. Pesquisa e políticas educativas. In: ZANTEN, A. V. (Org.) Dicionário de educação. Petrópolis: Vozes, 2011.

LIBÂNEO, J. C. Alguns aspectos da política educacional do governo Lula e sua repercussão no funcionamento das escolas. Revista HISTEDBR On-line, Campinas, n. 32, p. 168-178, dez. 2008.

MELO, M. A. Estado, governo e políticas públicas. IN: MICELI, S. (Org.). O que ler na ciência social brasileira (1970-1995). 2. ed. São Paulo: Sumaré: ANPOCS; Brasília, DF: CAPES, 1999.

MULLER, P; SUREL, Y. A análise das políticas públicas. Pelotas: Educat, 2002.

PALUMBO, D. J. A abordagem de política pública para o desenvolvimento político na América. In: SOUZA, E. C. B. M. de (Org.). Avaliação e formulação de políticas públicas em educação: leituras complementares. Brasília: MEC/UnB, 1998. p. 35-62. 
PARO, V. H. Políticas educacionais: considerações sobre o discurso genérico e a abstração da realidade. In: DOURADO, L. F.; PARO, V. H. (Orgs.). Políticas públicas e educação básica. São Paulo: Xamã, 2001. p. 29-48

SEPUlVEDA, J. A. M. O papel da Escola Superior de Guerra na projeção do campo militar sobre o campo educacional. 2010. 238 f. Tese (Doutorado em Educação) Universidade Federal do Rio de Janeiro, 2010.

SILVA, A. A. (Coord.) et al. Produção acadêmica em políticas educacionais no Brasil 2000-2010: dados dos programas conceito 5 ou mais. [Banco de dados]. Pesquisa financiada pelo CNPq, Edital/Chamada CNPq/CAPES no 07/2011. Feira de Santana: Cede, 2014. Disponível em: <http://www2.uefs.br/cede/docs/a-producao-academica-em-politicas-educacinais-20002010.pdf>. Acesso em: 12 fev. 2016.

SILVA, A. A.; JACOMINI, M. A. Introdução. In: SILVA, A. A.; JACOMINI, M. A. (Orgs.) Pesquisa em políticas educacionais: características e tendências. Feira de Santana: UEFS, 2016a. p. 13-32.

SILVA, A. A.; JACOMINI, M. A. Escolhas políticas e (re)direcionamentos epistemológicos: um panorama das teses e dissertações. In: SILVA, A. A; JACOMINI, M. A. (Orgs). Políticas em políticas educacionais: características e tendências. Feira de Santana: UEFS Editora, 2016b. p. 93-122.

SOUZA, C. Políticas públicas: uma revisão de literatura. Sociologias, Porto Alegre, ano 8, n. 16, p. 20-45, jul./dez. 2006. DOI: https://doi.org/10.1590/s1517-45222006000200003

TELLO, C.; MAINARDES, J. Revistando o enfoque das epistemologias da política educacional. Práxis Educativa, Ponta Grossa, v. 10, n. 1, p. 153-178, jan./jun. 2015. DOI: https://doi.org/10.5212/praxeduc.v.10i1.0007

TELLO, C.; MAINARDES, J. La posición epistemológica de los investigadores en Política Educativa: debates teóricos en torno a las perspectivas pos-estructuralista, neo-marxista y pluralista. Revista Archivos Analíticos de Políticas Educativas, v. 20, n. 9, p. 1-31, mar. 2012. DOI: http://dx.doi.org/10.14507/epaa.v20n9.2012

VIEIRA, C. E. Jornal diário como fonte e como tema para a pesquisa em História da Educação: um estudo da relação entre imprensa, intelectuais e modernidade nos anos de 1920. IN: OLIVEIRA, M. A. T. de (Org.). Cinco estudos em História e Historiografia da Educação. Belo Horizonte: Autêntica, 2007. p. 11-40.

Recebido em 12/10/2018

Versão corrigida recebida em 10/12/2018

Aceito em 14/12/2018

Publicado online em 18/12/2018 


\section{Antonia Almeida Silva}

Doutora em Educação pela USP. É professora titular do Departamento de Educação da Universidade Estadual de Feira de Sant'Ana (UEFS), onde atua na área de Política Educacional na Graduação e Pósgraduação. Membro do Grupo de Pesquisa CEDE/UEFS, que trabalha em articulação como HISTEDBa e o HISTEDBR. Autora de artigos e capítulos de livros na área de políticas educacionais.

\section{Márcia Aparecida Jacomini}

Doutora em Educação pela Faculdade de Educação da USP. Professora do Departamento de Educação da Escola de Filosofia, Letras e Ciências Humanas da Unifesp. Pesquisa Políticas Públicas para Educação e Gestão Escolar. Coordenado o Grupo de Estudo e Pesquisa em Política Educacional e Gestão escolar (Geppege). 